\title{
LONELINESS AND PREDICTIVE MODELS OF MULTIPLE RISK BEHAVIOR OF ADOLESCENTS IN THE CONTEXT OF ECOSYSTEM METATHEORY AND VIRTUAL INTERNET SPACE
}

\author{
Ján Kahan ${ }^{1}$, Eva Žiaková
}

\begin{abstract}
The metatheoretical ecosystem construct requires integrating the virtual dimension of the internet in the assessment of human living space.

Objective: The main goal of the present study is to identify possible relationships between loneliness, risk behavior in the use of psychoactive substances of adolescents, based on the ecosystem meta-frame of living space (which also reflects virtual space), as one of the essential factors in the emergence and development of addiction. Based on this, an effort is made to compile predictive models of multiple risk behaviors concerning the use of psychoactive substances.

Methods: Loneliness is determined using the OESL questionnaire. The RSi questionnaire examines risk behavior. Multiple linear regressions construct predictive models, and subcategories are subjected to correlations and parametric tests. At the same time, data on adolescents' loneliness are compared with data on the loneliness of addicted adult respondents and data on abstainers from another research.

File: The representative sample consists of 744 respondents in the second and third years of secondary schools in the Slovak Republic, of which 263 are men and 481 women. The research file of addicted respondents consists of 138 respondents (100 men, 38 women), and the research group of abstainers is 94 (58 men, 36 women).

Results: Statistically significant gender differences inexperienced social and emotional loneliness are found in adolescents and addicted respondents. For both male and female adolescents, excessive internet use is a significant predictor of psychoactive substance use. The prediction is more robust if, in adolescents, at least one parent suffers or has suffered from some kind of addiction.

Conclusions: Aspects of virtual space act as significant risk factors which, together with loneliness, create multiple risk conditions for risk behavior in the field of psychoactive substance use.
\end{abstract}

UDC Classification: 304, DOI: https://doi.org/10.12955/pss.v2.218

Keywords: Adolescents. Risk behavior. Loneliness. Addictions. Regression analysis. Metatheory.

\section{Introduction}

Virtual aspects of the internet are a common part of most people's daily lives. The internet forms its own virtual world, albeit parallel, but difficult to separate from the physical human habitat. The ecological niche incorporates a virtual dimension in which time and space are untied (Gitterman \& Germain, 2011). In the general understanding, loneliness is a negative emotional state (Perlman \& Peplau, 1982; Weiss, 1985a, 1985b, 1985c; Cacioppo \& Patrick, 2008), which does not relate exclusively to real physical space. To escape the difficult feelings of loneliness, one may find oneself in a virtual world where one seeks to saturate basic emotional needs (Chen, 2010; Oskenbay et al., 2015). The pseudo-values offered by substance and non-substance addictions, including those associated with excessive internet use, can never satisfy the basic human needs of affiliation, intimacy, and love. Unsaturation or complete deficiency of these needs causes the experience of social or emotional loneliness (Maslow, 2013; Lyons et al., 2010; Frankl, 1963; Weiss, 1985a, 1985b, 1985c; Cacioppo \& Patrick, 2008). Basic human needs in the emotional or spiritual realm cannot be met through drugs (Alcoholics Anonymous, 2001; Frankl, 1963; Griffiths, 2005). People addicted to alcohol or using psychoactive substances show greater feelings of loneliness than other sections of the population, whether loneliness is a predictor or a consequence of use or addiction (Rokach, 2002; Medora \& Woodward 1991; Akerlind \& Hornquist 1992). Regardless of whether it is a substance or non-substance addiction, the principles and factors determining the origin and development of addiction are similar (Martin \& Petry, 2005; Ali, 2021; Zou et al., 2017). Addiction is always the result of several aspects, biological and genetic levels of man, psychological constitution and at the same time conditioned by the very structural characteristics of addictive substances/activities in the context of the influence of the social environment (Griffiths, 1999, 2005). Finding the relationships between loneliness and risk behavior in the use of psychoactive substances of adolescents, based on the ecosystem meta-framework of living space (in which virtual space is also reflected) is one factor

\footnotetext{
${ }^{1}$ Pavol Jozef Šafárik University in Košice, Faculty of Arts, Department of Social Work, Košice, Slovak Republic, eva.ziakova@upjs.sk, https://orcid.org/0000-0002-8126-5451

${ }^{2}$ Pavol Jozef Šafárik University in Košice, Faculty of Arts, Department of Social Work, Košice, Slovak Republic, jan.kahan@upjs.sk, orcid.org/0000-0002-1996-1894
} 
determining the emergence and development of addiction. This study's main objective is to demonstrate that risk behavior in virtual space beyond the real world with environmental factors that may increase the risk of the emergence and development of substance / non-substance dependence. In most cases, no risk behavior occurs separately but simultaneously with other types of risky behavior such as various combinations of regular alcohol use, sexual risk behavior, psychoactive substance use, criminal, violent, or delinquent behavior, school neglect, mood disorders, and physical injuries (MacArthur et al., 2012; McCambridge et al., 2011; Baliunas et al., 2010; Kaess et al., 2014). The aim is also to find out what combinations of multiple risk behaviors are present in Slovak adolescents, which predict risk behaviors in psychoactive substance use. Based on this, an effort is made to compile predictive models of multiple risk behaviors to the use of substance / non-substance dependence. Environmental factors are not just about the physical environment. The simultaneous action and intertwining of the real and virtual worlds are likely to cause a person to be exposed to multiple risks of these levels, which, together with loneliness, may lead to risky behavior in the field of substance and non-substance addictions (Stickley et al., 2014) and subsequent development of addiction. We assume that the virtual space in the form of risky behavior on social networks (F2) and excessive use of the internet (F4) will be statistically significantly related to the risk behavior in the field of psychoactive substance use (Hypothesis 1a). At the same time, we assume that there is a statistically significant relationship between loneliness (social, emotional, general) and risk behavior in the field of substance use (F3) (Hypothesis 1b). The family represents the person's closest environment, and every dysfunction in the family is reflected in the family system as an inability to satisfy its members' needs sufficiently. A particularly risk factor for optimal human development is when there is an addicted parent in the family (Woititz, 2002; Hanć et al., 2015; Bays, 1990; McKeganey, 2002; Lochman \& Steenhoven, 2002). Based on this, we assume that the emotional needs of adolescents who have at least one parent of a substance / non-substance addict are not sufficiently satisfied and are therefore more lonely than adolescents who do not have an addicted parent (Hypothesis 2). A seven-year study of adolescents showed that regular recreational alcohol use risk behavior is a strong predictor of alcohol dependence (Bonomo et al., 2004; MacArthur et al., 2012). The statement used in Jelinek's (1952) definition of the development of alcohol dependence corresponds to the first phase of addiction. It has been found that people addicted to alcohol or taking other psychoactive substances are more isolated than other groups of the population (Rokach, 2002; Medora \& Woodward, 1991; Akerlind \& Hornquist, 1992). We assume that there are differences in the degree of loneliness between adolescents who behave at risk of substance use and hospitalized addicted respondents, even compared to abstainers who have overcome addiction and are in the aftercare process (Hypothesis 3 ). This assumption is also based on the fact that loneliness can develop simultaneously with loneliness (Akerlind \& Hornquist, 1992; Hosseinbor et al., 2014; Rokach \& Orzeck, 2013; Rokach, 2002). Male and female adolescents may have different risk behavior tendencies, emphasizing sexual risk behavior (Stickley et al., 2014; Lawal \& Idemudia, 2018), so adolescents are gender-segregated in some calculations.

\section{Methods}

Design

The quantitative design of the study compares and integrates data from two independent studies that have worked with quantitative data ex-post facto (Klassen et al., 2012; Campbell et al., 2017).

\section{Respondents}

\section{Research sample 1}

The research group of a random selection of adolescents consists of 744 respondents in the second and third years of secondary schools in the Slovak Republic, 263 men and 481 women (Mean age $=16.94$, Median age $=17, \mathrm{SD}=0.806$ ). This is a representative study for which key data were collected in November and December 2019 and January 2020 (Kahan et al., 2021 in press).

\section{Research sample 2}

The research group of addicted respondents consists of 138 respondents (100 men and 38 women; Mean age $=39.45$, Median age $=38.5, \mathrm{SD}=12.753$ ) obtained intentionally from the Centers for Drug Addiction Treatment and the Specialist Psychiatric Institute in Predná Hora. The study set of abstainers consists of 94 respondents ( 58 men and 36 women; Mean age $=47.18$, Median age $=48.5$, 
$\mathrm{SD}=13.31$ ), obtained from self-help and psychotherapeutic groups. Respondents were targeted based on voluntariness and availability. For purposes of the presented study, no differences are made between the respondents about the type of substance and non-substance dependence and their combinations. Therefore, all respondents are included in the file, regardless of the diagnosis. Dividing respondents by kind of dependency would significantly reduce the number of files. Data collection took place from December 2018 to March 2019 (Kahan \& Žiaková, 2019).

\section{Measures}

The method of obtaining data from the respondents was provided using questionnaire batteries. Since these are two different studies, the batteries were also other. For the purposes of this study, we are measuring tools that are relevant in this case.

\section{DJGLS}

In both studies, a De Jong Gierveld Loneliness Scale (DJGLS) measurement tool was used to capture the degree of social, emotional, and aggregate overall loneliness (Gierveld, 1987; Gierveld \& Tilburg, 2021). According to the manual of the loneliness scale (Gierveld \& Tilburg, 2021) (OESL - Overal, Emotional, and Social Loneliness), it is possible to determine the degree of total, emotional and social loneliness. Respondents answer the given statements by expressing their consent on a scale from 5 to 1 , while the scale is dichotomized in the further calculations (min. 0 - max. 11). A higher score indicates a higher degree of loneliness. The instrument's reliability has a value of Cronbach's $\alpha=0.84$ for the original authors and for the individual dimensions of emotional loneliness $-\alpha=0.88$ and social loneliness $-\alpha=0.88$ (Gierveld, 1987; Gierveld \& Tilburg, 2021). In our case, the reliability values were lower but still at a good level (Grayson, 2004; Johnson \& Johnson, 2009). For the whole questionnaire as a one-dimensional scale of total loneliness $-\alpha=0.81$, for emotional subscale $-\alpha=$ 0.72 and social subscale $-\alpha=0.79$. For addicts, the Cronbach values of total loneliness are $-\alpha=0.83$, for the emotional subscale $-\alpha=0.76$ and for the social subscale $-\alpha=0.8$. Reliability values for abstinent respondents are in total loneliness $-\alpha=0.85$, for emotional subscale $-\alpha=0.78$ and social subscale $-\alpha=0.78$. Average values are used when comparing the individual dimensions of loneliness, as the DJGL scale contains 11 items, of which 6 monitors emotional loneliness and 5 monitors social loneliness.

RSi

The questionnaire "adolescent risk behavior" (referred to as $\mathrm{RSi}$ ) was used in the operationalization and quantification of individual categories of risk behavior (Kahan et al., 2021 in press; Lovašová, 2021). Detection of risk behavior is based on integrative constructs based on human ontogenesis, psychopathology and ecosystem metatheory, and problem behavior theory (Jessor, 1992, 2014). It is a research questionnaire (introductory author's research) that monitors seven relatively separate (factors) categories of risk behavior through interval scales of agreement from 1 to 7 ( 1 - strongly disagree; 7 strongly agree) (Kahan et al., 2021 in press; Lovasova, 2021). These categories are bullying and delinquency (F1), risk behavior on social networks (F2), substance and non-substance use (F3), internet abuse (F4), self-harm and suicidal behavior (F5), sexual risk behavior (F6), racism and xenophobia (F7). The questionnaire focuses on the occurrence of risky behavior in the last year. The values of the individual dimensions are as follows - F1 $\alpha=0.65, \mathrm{~F} 2 \alpha=0.68, \mathrm{~F} 3 \alpha=0.81, \mathrm{~F} 4 \alpha=0.72$, $\mathrm{F} 5 \alpha=0.73, \mathrm{~F} 6 \alpha=0.69$ and F7 $\alpha=0.55$ (Kahan et al., 2021 in press). A higher score indicates a higher level of behavior in a particular risk area, but the entire questionnaire can also be used as the sum of the scores of all items. The given questionnaire (RSi) achieves the internal consistency of the whole questionnaire in the presented research $-\alpha=0.86$, which we consider to be a sufficiently powerful tool (Kahan et al., 2021 in press; Johnson \& Johnson, 2009). The overall reliability of the version of the RSi questionnaire for the original author (Lovašová, 2021) reached the value $\alpha=0.88$.

Demographic data in both surveys were obtained based on respondents' subjective statements. Even in the case where adolescents were asked a question about their parents' addiction, to which they answered one of the options (My parents: a) never suffered from any addiction, b) one of them was/is addicted, c) both were/are addicted). It is clear that in this case, it cannot be an accurate diagnosis of addiction according to diagnostic criteria (this was not the goal), but the fact that adolescents label their parents as addicts suggests that parents are likely to significantly neglect family needs at the expense of alcohol or drug. Averages are used when comparing individual dimensions of risk 
behavior, as respective categories of risk behavior contain different numbers of items (Kahan et al., ca. 2021).

\section{Statistical analyses}

Selected data from both surveys were adjusted so that they could be compared with each other. Based on the Shapiro-Wilk test $(\mathrm{p}>0.05)$, visual inspection of the histogram, Q-Q probability graph, skewness, and kurtosis, a null hypothesis rejection was concluded (Table 1, Table 2) (Cramer, 1997 Doane \& Seward, 2011). Statistical analysis of normality of sample data did not show a normal distribution (Schmider et al., 2010; Shapiro \& Wilk, 1965; Razali \& Wah, 2011). However, the central least-squares limit theorem guarantees that abnormally distributed data can be used in parametric statistics and linear regression, provided that the number of respondents in the sample is large enough, which we consider being a valid assumption given the robustness of the T-test (Fraser et al., 1999; Barber \& Thompson, 2000; Sawilowsky \& Blair, 1992).

\begin{tabular}{|c|c|c|c|c|c|c|c|c|}
\hline & & $\mathrm{N}$ & Mean & SD & Skew & SE & Kurtosis & SE \\
\hline \multirow{3}{*}{$\begin{array}{l}\text { Emotional } \\
\text { Loneliness }\end{array}$} & Adolescents & 744 & .347 & .30 & .654 & .090 & -.618 & .179 \\
\hline & Addicted & 138 & .547 & .33 & -.190 & .206 & -1.206 & .409 \\
\hline & Abstainers & 94 & .331 & .32 & .841 & .248 & -.4138 & .492 \\
\hline \multirow{3}{*}{$\begin{array}{l}\text { Social } \\
\text { Loneliness }\end{array}$} & Adolescents & 744 & .408 & .35 & .336 & .089 & -1.186 & .179 \\
\hline & Addicted & 138 & .529 & .36 & -.148 & .206 & -1.371 & .409 \\
\hline & Abstainers & 94 & .438 & .34 & .145 & .248 & -1.187 & .492 \\
\hline \multirow{3}{*}{$\begin{array}{l}\text { Overal } \\
\text { Loneliness }\end{array}$} & Adolescents & 744 & .375 & .28 & .546 & .089 & -.724 & .179 \\
\hline & Addicted & 138 & .538 & .29 & -.206 & .206 & -1.121 & .409 \\
\hline & Abstainers & 94 & .380 & .29 & .662 & .248 & -.496 & .492 \\
\hline
\end{tabular}

\begin{tabular}{|l|l|l|l|l|l|l|l|l|}
\hline Table 2: Descriptive Statistics Associated with Risk Behavior of Adolescents \\
\hline Rsi & $\mathrm{N}$ & Mean & Med & SD & Skew & SE & Kurtosis & SE \\
\hline RSi F 1 mean & 744 & 2.55 & 2.25 & 1.30 & .962 & .090 & .5319 & .179 \\
\hline RSi F 2 mean & 744 & 1.78 & 1 & 1.21 & 1.824 & .090 & 3.029 & .179 \\
\hline RSi F 3 mean & 744 & 3.84 & 3.8 & 1.84 & .064 & .090 & -1.167 & .179 \\
\hline RSi F 4 mean & 744 & 4.15 & 4.2 & 1.44 & -.110 & .090 & -.711 & .179 \\
\hline RSi F 5 mean & 744 & 2.91 & 2.67 & 1.73 & .799 & .090 & -.263 & .179 \\
\hline RSi F 6 mean & 744 & 1.83 & 1 & 1.37 & 1.873 & .090 & 3 & .179 \\
\hline RSi F 7 mean & 744 & 2.06 & 1.5 & 1.42 & 1.591 & .090 & 2.212 & .179 \\
\hline Overall Rsi mean & 744 & 2.87 & 2.81 & .94 & .360 & .090 & -.263 & .179 \\
\hline Source: Authors
\end{tabular}

We are aware that in regression models, some or all predictive variables may be related to each other, but multicollinearities generally do not prevent us from predicting (Kutner et al., 2005). Descriptive and inference surveys were performed using IBM SPSS Statistics 20. Subsequently, research hypotheses were verified and evaluated as quantitative data (Campbell et al., 2017; Pallant, 2007). We recognize that selective comparisons of disproportionate data present some inconsistencies. Still, a deeper reflection on the proposed contexts and results may offer a different view of substance use in online risk behavior and multiple risk behaviors as factors that may increase the risk of alcohol and drug use.

\section{Results}

\section{Results of correlation analyzes of factors of risk behavior and loneliness}

Mutual correlations of risk behavior (Table 3) indicate weak to moderate relationships between types of risk behavior, so we can consider the individual categories relatively independent. The first strongest correlation $\left(\mathrm{r}_{\mathrm{s}}=.428, \alpha<.001\right)$ is between excessive internet use (F4) and psychoactive substance use $(\mathrm{F} 3)$. The second strongest correlation $\left(\mathrm{r}_{\mathrm{s}}=.428, \alpha<.001\right)$ is between sexual risk behavior (F6) and substance use (F3). At least two facts follow from the above. The first is that the virtual space in the form of excessive use of the internet $(\mathrm{F} 4)$ enters into the physical reality of risky substance use (F3) (Hypothesis 1a) and at the same time into the relationship with sexual risk behavior. The second is that the risk factor for excessive internet use (F4) correlates with all other 
types of risk behavior, which assumes that possible combinations of multiple risk behaviors will be associated to varying degrees with the virtual world of the internet.

\begin{tabular}{|c|c|c|c|c|c|c|c|}
\hline \multicolumn{2}{|c|}{ Spearman } & & & & & & \\
\hline \multirow{2}{*}{\multicolumn{2}{|c|}{\begin{tabular}{l|l} 
Sig. (2-tailed) N 744 \\
$\mid r_{s}$
\end{tabular}}} & RSi F 1 & RSi F 2 & RSi F 3 & RSi F 4 & RSi F 5 & RSi F 6 \\
\hline & & $.263 * *$ & & & & & \\
\hline RSi F 2 & $p(\alpha)$ & $<.001$ & & & & & \\
\hline \multirow[b]{2}{*}{ RSi F 3} & $r_{\mathrm{s}}$ & $.399 * *$ & $.237 * *$ & & & & \\
\hline & $p(\alpha)$ & $<.001$ & $<.001$ & & & & \\
\hline \multirow[b]{2}{*}{ RSi F 4} & $\mathrm{r}_{\mathrm{s}}$ & $.343 * *$ & $.335 * *$ & $.428 * *$ & & & \\
\hline & $p(\alpha)$ & $<.001$ & $<.001$ & $<.001$ & & & \\
\hline \multirow[b]{2}{*}{ RSi F 5} & $\mathrm{r}_{\mathrm{s}}$ & $.171 * *$ & $.352 * *$ & $.306^{* *}$ & $.388 * *$ & & \\
\hline & $p(\alpha)$ & $<.001$ & $<.001$ & $<.001$ & $<.001$ & & \\
\hline \multirow[b]{2}{*}{ RSi F 6} & $r_{\mathrm{s}}$ & $.174 * *$ & $.177 * *$ & $.426 * *$ & $.215^{* *}$ & $.143 * *$ & \\
\hline & $p(\alpha)$ & $<.001$ & $<.001$ & $<.001$ & $<.001$ & $<.001$ & \\
\hline \multirow[b]{2}{*}{ RSi F 7} & $\mathrm{r}_{\mathrm{s}}$ & $.234 * *$ & $.174 * *$ & $.135 * *$ & $.223 * *$ & $.117 * *$ & .048 \\
\hline & $p(\alpha)$ & $<.001$ & $<.001$ & $<.001$ & $<.001$ & $<.001$ & .189 \\
\hline \multicolumn{8}{|c|}{$* * \mathrm{p} \alpha<.01$} \\
\hline \multicolumn{8}{|c|}{ Source: Kahan et al. (2021 in press) } \\
\hline
\end{tabular}

The assumption of hypothesis 1b was not confirmed (Table 4). Based on the data obtained, we cannot claim that loneliness (social, emotional, general) has a significant correlation with risk behavior in the field of psychoactive substances (F3). However, there are relationships between loneliness and risky behavior on the internet (F2), excessive internet use (F4), and the strongest relationship $\left(\mathrm{r}_{\mathrm{s}}=.404 \alpha\right.$ $<.001$ ) is between emotional loneliness and self-harm (F5). Self-harm and suicidal tendencies (F5) are significantly related to excessive internet use (F4) (Table 3) $\left(\mathrm{r}_{\mathrm{s}}=.388, \alpha<.001\right)$. From the above findings, it can be concluded that if adolescents experience some form of loneliness, they can be distracted in the virtual environment of the internet, along with self-harm and suicidal thoughts. These relationships are supported by a study by Durkee et al. (2011), in which pathological internet users who met the criteria of internet dependence, but also those who behaved maladaptively in the field of internet use, showed significantly higher rates of depression, self-harm, and suicidal behavior compared to other students.

\begin{tabular}{|c|c|c|c|c|c|c|c|c|c|c|}
\hline \multicolumn{3}{|c|}{ Spearman } & & & & & & & & \\
\hline \multicolumn{3}{|c|}{ Sig. (2-tailed) N 744} & RSi F1 & RSi F2 & RSi F3 & RSi F4 & RSi F5 & RSi F6 & RSi F7 & Total RSi \\
\hline \multirow{6}{*}{ DJGLS } & \multirow[b]{2}{*}{ Emotional loneliness } & $\mathrm{r}_{\mathrm{s}}$ & .01 & $.139^{* *}$ & -.03 & $.191^{* *}$ & $.404^{* *}$ & -.01 & .05 & $.154^{* *}$ \\
\hline & & $p(\alpha)$ & .77 & $<.001$ & .43 & $<.001$ & $<.001$ & .88 & .20 & $<.001$ \\
\hline & \multirow[b]{2}{*}{ Social loneliness } & $r_{s}$ & -.01 & .07 & $-.073^{*}$ & .06 & $.234^{* *}$ & .01 & .05 & .06 \\
\hline & & $p(\alpha)$ & .90 & .07 & .05 & .08 & $<.001$ & .89 & .21 & .09 \\
\hline & \multirow[b]{2}{*}{ Total loneliness } & $r_{s}$ & $<.001$ & $.125^{* *}$ & -.07 & $.143^{* *}$ & $.362^{* *}$ & $<.001$ & .05 & $.118^{* *}$ \\
\hline & & $p(\alpha)$ & .99 & $<.001$ & .08 & $<.001$ & $<.001$ & .97 & .14 & $<.001$ \\
\hline
\end{tabular}

The loneliness of adolescents and dependence of their parents - results of independent T-tests

Satisfying emotional needs as one of the basic functions of the family system led us to the further assumption that respondents who have at least one addicted parent are more lonely than their nondependent peers (Hypothesis 2). Table 5 shows the statistically significant average difference in the degree of emotional loneliness $(\mathrm{t}(726)=2.315, \mathrm{p}<.05)$ and total loneliness $(\mathrm{t}(726)=2.272, \mathrm{p}<.05)$. Adolescents who have stated that they have at least one parent addicted on average values experience a greater degree of loneliness than their peers, whose parents are not dependent on their answers. However, the statement has a relatively low informative value due to the low strength of Cohen's d effect size.

\section{Regression models for predicting F3 risk behavior (psychoactive substance use) in adolescents}

In adolescents who do not have addicted parents in predicting substance and non-substance dependencies, several risk behaviors factors, along with loneliness, enter into the model of multiple 


\begin{tabular}{|c|c|c|c|c|c|c|c|}
\hline & \multicolumn{2}{|c|}{$\begin{array}{l}\text { Addiction of parrent/s } \\
-\mathrm{NO}\end{array}$} & \multicolumn{2}{|c|}{$\begin{array}{l}\text { Addiction of parrent/s } \\
\text { - YES }\end{array}$} & \multirow[b]{2}{*}{$\mathrm{t}(726)$} & \multirow[b]{2}{*}{$\mathrm{p}$} & \multirow[b]{2}{*}{ Cohenn's d } \\
\hline & $\mathrm{M}$ & SD & $\mathrm{M}$ & SD & & & \\
\hline $\begin{array}{l}\text { Emotional } \\
\text { Loneliness Mean }\end{array}$ & .33 & .29 & .39 & .31 & 2.31 & .021 & .2 \\
\hline $\begin{array}{l}\text { Social Loneliness } \\
\text { Mean }\end{array}$ & .4 & .34 & .44 & .37 & 1.58 & .114 & .1 \\
\hline $\begin{array}{l}\text { Overall Loneliness } \\
\text { Mean }\end{array}$ & .36 & .27 & .41 & .29 & 2.27 & .023 & .2 \\
\hline
\end{tabular}

risk behaviors. The predominant risk factor is Internet overuse (F4). Social loneliness also enters the model for men, and women, total loneliness (Table 6). The prediction is more robust in adolescents if at least one parent is addicted. For these respondents, only three but strongly dominant factors are included in predicting psychoactive substance use. Both in men and women, the most substantial factors are in the form of virtual space (F4) and sexual risk behavior (F6). In men, the given prediction (F4, F6, F1) explains $40.6 \%$ of risk behavior in the field of psychoactive substance use (F3) (Table 7). For women, $44.2 \%$ of women in the use of psychoactive substances (F3) explain sexual risk behavior (F6) and risk behavior on social networks (F2) together with bullying and delinquency (Table 7). The presenting findings point to the fact that if a parent or both parents suffer from forms of addiction is significantly reflected in the states of risk behavior.

Table 6: Model of prediction of dependent variable F3 (use of psychoactive substances) dependence of parent(s) - NO

\begin{tabular}{|c|c|c|c|c|c|c|}
\hline \multicolumn{2}{|c|}{ Men + women } & $\mathrm{R}$ & $\mathrm{R}^{2}$ & $\mathrm{df}$ & $F$ & $\mathrm{p} \alpha$ \\
\hline \multirow{2}{*}{ RSi F3 } & $\mathrm{M}$ & .587 & .344 & $4 ; 180$ & 23.635 & $<.001$ \\
\hline & W & .655 & .429 & $5 ; 361$ & 54.196 & $<.001$ \\
\hline \multicolumn{2}{|c|}{ Regression coefficient, T-test } & B & SD & Beta & $t$ & $\mathrm{p} \alpha$ \\
\hline \multirow{4}{*}{ Men } & RSi F 4 & .289 & .079 & .234 & 3.625 & $<.001$ \\
\hline & RSi F 6 & .328 & .119 & .172 & 2.739 & .006 \\
\hline & Social loneliness & -1.028 & .301 & -.209 & -3.410 & $<.001$ \\
\hline & RSi F 1 & .602 & .111 & .354 & 5.429 & $<.001$ \\
\hline \multirow{5}{*}{ Women } & RSi F 4 & .378 & .057 & .295 & 6.583 & $<.001$ \\
\hline & RSi F 6 & .471 & .070 & .279 & 6.711 & $<.001$ \\
\hline & RSi F 5 & .474 & .083 & .265 & 5.702 & $<.001$ \\
\hline & Overal loneliness & -.609 & .138 & -.192 & -4.394 & $<.001$ \\
\hline & RSi F 1 & .322 & .084 & .164 & 3.805 & $<.001$ \\
\hline
\end{tabular}

$\mathrm{p} \alpha<.001$

Source: Authors

Table 7: Model of prediction of dependent variable F3 (use of psychoactive substances) dependence of parent(s) - YES

\begin{tabular}{|c|c|c|c|c|c|c|}
\hline \multicolumn{2}{|c|}{ Men + women } & $\mathrm{R}$ & R2 & df & $\mathrm{F}$ & $\mathrm{p} \alpha$ \\
\hline \multirow{2}{*}{ RSi F3 } & $\mathrm{M}$ & .637 & .406 & $3 ; 68$ & 15.487 & $<.001$ \\
\hline & W & .665 & .442 & $3 ; 103$ & 26.392 & $<.001$ \\
\hline \multicolumn{2}{|c|}{ Regression coefficient, T-test } & B & SD & Beta & $\mathrm{t}$ & $\mathrm{p} \alpha$ \\
\hline \multirow{3}{*}{ Men } & RSi F 4 & .299 & .131 & .23 & 2.284 & .025 \\
\hline & RSi F 6 & 486 & .165 & .298 & 2.936 & .004 \\
\hline & RSi F 1 & .51 & .165 & .324 & 3.092 & .002 \\
\hline \multirow{3}{*}{ Women } & RSi F 6 & .559 & .122 & .355 & 4.562 & $<.001$ \\
\hline & RSi F 2 & .428 & .117 & .276 & 3.641 & $<.001$ \\
\hline & RSi F 1 & .652 & .144 & 357 & 4.515 & $<.001$ \\
\hline
\end{tabular}

Specific gender differences are shown both in the experience of loneliness (Table 6) and in the forms of risk behavior (Table 6, Table 7). However, in all multiple regression models of substance use prediction, virtual space enters this prediction as to the dominant risk factor in the form of Internet 
overuse (F4) (Table 6, Table 7), or risk behavior on social networks (F2) (Table 6, women) (Hypothesis 1a). Our regression models are also supported by a study that showed a link between loneliness and substance use in adolescents in the Russian Federation and the United States of America (Stikley et al., 2014). The study also showed a relationship between loneliness and sexual risk behavior in Russian girls. In our models for predicting substance use (Table 6, Table 7), sexual risk behavior is one of the predominant factors in the prediction, primarily in women (Table 7).

Experiencing loneliness among adolescents, addicted and abstinent respondents - results of independent $T$-tests

Based on the average values of risk behavior in the field of psychoactive substance use (F3) $(\mathrm{M}=$ $3.84, \mathrm{SD}=1.838$ ) of adolescents (Table 2), those adolescents who achieved an F3 score $\geq$ of 3.8 in the number of $\mathrm{N}=380$ are selected, i.e., they behaved riskier in use of psychoactive substances as their peers. According to Jelinek (1952), risk behavior in the field of psychoactive substance use represents the first phase of the possible origin and development of addiction. Given that loneliness can develop simultaneously with loneliness (Akerlind \& Hornquist, 1992; Hosseinbor et al., 2014; Rokach \& Orzeck, 2013; Rokach, 2002), possible connections and conclusions about loneliness are drawn based on the assumptions of existing differences, substance use and abstinence (Table 8) (Hypothesis 3).

\begin{tabular}{|c|c|c|c|c|c|c|c|c|c|}
\hline & \multicolumn{2}{|c|}{ Adolescents } & \multicolumn{2}{|c|}{$\begin{array}{l}\text { Addicted / } \\
\text { hospitalized }\end{array}$} & \multicolumn{2}{|c|}{\begin{tabular}{|l} 
Addicted / \\
abstainers
\end{tabular}} & \multirow[b]{2}{*}{$\begin{array}{l}\mathrm{t}\left(516^{*} ; 230^{* *} ;\right. \\
\left.472^{* * * *}\right)\end{array}$} & \multirow[b]{2}{*}{$\mathrm{P}$} & \multirow[b]{2}{*}{ Cohen's d } \\
\hline & M & SD & M & SD & M & SD & & & \\
\hline \multirow{3}{*}{$\begin{array}{l}\text { Emotional } \\
\text { Loneliness Mean }\end{array}$} & .34 & .30 & .55 & .33 & & & $6.82^{*}$ & $<.001$ & .66 \\
\hline & & & .55 & .33 & .33 & .32 & $4.93^{* *}$ & $<.001$ & .66 \\
\hline & .34 & .30 & & & .33 & .32 & $.15^{* * *}$ & .881 & .01 \\
\hline \multirow{3}{*}{$\begin{array}{l}\text { Social Loneliness } \\
\text { Mean }\end{array}$} & .39 & .34 & .53 & .36 & & & $4.09^{*}$ & $<.001$ & .4 \\
\hline & & & .53 & .36 & .44 & .34 & $1.92^{* *}$ & .056 & .26 \\
\hline & .39 & .34 & & & .44 & .34 & $.128^{* * *}$ & .2 & .14 \\
\hline \multirow{3}{*}{$\begin{array}{l}\text { Overall } \\
\text { Loneliness Mean }\end{array}$} & .36 & .28 & .54 & .29 & & & $6.37^{*}$ & $\begin{array}{l}<.001 \\
\end{array}$ & .62 \\
\hline & & & .54 & .29 & .38 & 0.29 & $4.01^{* *}$ & $<.001$ & .54 \\
\hline & .36 & .28 & & & .38 & 0.29 & $.62^{* * * *}$ & .53 & .07 \\
\hline
\end{tabular}

There are statistically significant differences inexperienced social and emotional loneliness between adolescents and addicted respondents and between addicted and abstinent respondents (Table 8). The difference between abstainers and adolescents is not statistically significant, and these findings suggest pleasing results for both abstainers and adolescents. Abstinent people are obtained from therapeutic and self-help groups, in which dynamic processes take place in the restructuring of attitudes in selfcare. Suppose there are no significant average differences in the loneliness experienced between groups of abstainers and adolescents. In that case, this presupposes good therapeutic conditions and results in abstainers, and in most cases, it also indicates optimal developmental disorders in adolescents.

\section{Discussion}

Multiple risks and addictive behaviors in the virtual world and physical ecosystem in the context of psychoactive substance use

The ecosystem metatheory offers social workers a way to think and assess the context of people's life situations in social and physical environmental influences (Kemp et al., 1997). The parallel existing virtual world modifies and influences the entire traditional habitat and niche. This also applies to sociopathological phenomena. This is also indicated by our finding (Table 3 ) that there is a moderately correlated relationship between excessive Internet use (F4) and psychoactive substance use (F3) ( $r_{s}=$ $.428, \alpha<.001)$. Given hypothesis $1 \mathrm{a}$ is also supported by regression models for predicting the use of psychoactive substances, in which virtual space enters as a dominant risk factor in the form of Internet overuse (F4) (Table 6, Table 7) or risk behavior on social networks (F2). (Table 6, women). The finding is also supported by a study of adolescents, which found the same relationships between Internet addiction and substance use with family risk factors, including a positive relationship between parents and substance use (Yen et al., 2007). Family risk factors create a level playing field for 
substance and/or non-substance dependence (Hosseinbor et al., 2014; Yen et al., 2007; Lochman \& Steehnhoven, 2002). In our study, we found that adolescents who declared a dependent parent/parents experienced emotional loneliness to a greater extent than their peers $(\mathrm{t}(726)=2.315, \mathrm{p}<.05)$, but the strength of the relationship is relatively low (Cohen's d 0.2) (Table 5). The family and social environment influenced by the untying of time and space, the creation of optimal conditions of intersubjective and interpersonal processes in family, group, and community life of the physical world encounters problems of intimacy (Hosseinbor et al., 2014), privacy, and basic needs entered into the virtuality of cyberspace. People and their environment are considered interdependent. They are part of the reciprocal exchange of a complex system operating in a time in which man and the environment as a whole are constantly changing and forming with each other (Kemp et al., 1997; Gitterman \& Germain, 2011). At the same time, risk factors of the physical world, moderated, mediated or multiplied by aspects of virtual space, enter into this reciprocal exchange (Durkee et al., 2016). Correlation analysis (Table 3) revealed the strongest relationships between excessive internet use (F4) and psychoactive substance use $(\mathrm{F} 3)\left(\mathrm{r}_{\mathrm{s}}=.428, \alpha<.001\right)$ and between sexual risk behavior $(\mathrm{F} 6)$ and use psychoactive substances $(\mathrm{F} 3)\left(\mathrm{r}_{\mathrm{s}}=.428, \alpha<.001\right)$. Multiple exposures to physical and virtual risk factors (Table 6, Table 7) can cause adolescents to be riskier in substance use and spend excessive amounts of time online, followed by circular incentives for other risky behavior. Spending an excessive amount on the Internet can cut a person off from real social contacts, thus ceasing to satisfy the basic needs of intimacy, affiliation naturally, and love, which is then reflected in the solitude experienced about themselves and the world around them (Cacioppo \& Patrick, 2008; Erdoğan, 2008). Loneliness can lead to psychoactive substances in adolescents as a way out of the feeling of loneliness or as a form of satisfying emotional and psychological needs (Page \& Cole, 1991). Our other correlations (Table 4) did not show relationships between loneliness and risk behavior in the area of risky substance use. But loneliness entered into relationships with risk behavior on social networks (F2), excessive use of the Internet (F4), and these subsequently entered into a relationship with risk behavior in the field of psychoactive substance use (F3) (Table 3, Table 6, Table 7). The strongest relationship was shown between self-harm and suicidal tendencies (F5) and emotional loneliness ( $\mathrm{r}_{\mathrm{s}}=$ $.404, \alpha<.001)$ (Table 4), and also in relation to excessive internet use (F4) (Table 3) $\left(\mathrm{r}_{\mathrm{s}}=.388, \alpha\right.$ $<.001)$. Pathological or maladaptive Internet use is statistically significant with depression, self-harm, and suicidal behavior (Durkee et al., 2011). The finding again points to a deficit in the saturation of emotional needs and some compensation through the Internet. Predictive models of risk behavior in the field of psychoactive substance use F3 (Table 6, Table 7) in the contextual consideration of ecosystem metatheology and virtual space of the Internet clearly conclude that substance and nonsubstance addictions have become part of cyberspace in which the weakened or absent influence of social formal control agents. Therefore, we believe that cyberspace needs to be perceived as a "new" factor that can significantly negatively moderate or mediate the perspective of psychoactive substance use, even to loneliness. Based on this consideration, the differences between loneliness in high-risk adolescents (in the area of psychoactive substances), who achieved an F3 score $\geq$ of 3.8, compared to addicted respondents and abstinent addicts who are in an active aftercare process, i.e., regularly participate in psychotherapeutic or self-help groups. People addicted to alcohol or using psychoactive substances show greater feelings of loneliness than other sections of the population, whether loneliness is a predictor or a consequence of psychoactive substance use or addiction (Rokach, 2002; Medora \& Woodward, 1991; Akerlind \& Hornquist, 1992; Cacioppo et al., 2002). Our research confirmed this statement (Table 8). Addicted respondents achieved the highest average values of experienced loneliness in comparison with adolescents, as well as in comparison with abstainers. This finding is positive concerning the prospect of abstinence in addicted people, as well as with adolescents, given that loneliness is one of the negative emotional states, categorized as risk situations that create conditions for relapse (Marlatt \& Gordon, 1985; Marlatt, 1996; Hosseinbor et al., 2014). Although the selected adolescents were at risk of substance use, they achieved a lower average value of emotional, social, and overall loneliness as addicted respondents and abstainers, but no statistically significant difference was found between adolescents and abstainers. As mentioned, we consider this fact to be positive, both on the part of adolescents and abstainers. We assume that the psychotherapeutic and self-help groups from which the abstainers were obtained generally focused on abstinence. However, for an addicted person to become abstinent, rebuild his life and take an active relationship with his being, he needs to share his inner world through a supportive relationship in the sphere of participation 
and in the context of a social environment in which one becomes an observer and participant in one's own change (Volpicelli \& Szalavitz, 2000; Gitterman \& Germain, 2011). Cognition, emotions, behavior take into account three aspects of human life. The philosophical or spiritual level opens up space for change at a deeper level. Own profound philosophical change of attitudes to life, confrontation and answering existential questions, and fulfillment of life with real meaning led people to a total change beyond cognitions, emotions, and behavior (Ellis \& Ellis, 2013; Alcoholics Anonymous, 2001; De Leon, 2000). In Slovakia, alcohol consumption is deeply habitualized, and it seems that the given problem is exhaustively researched and thoroughly captured. Revised statistics on alcohol-related mortality in Slovakia shed new light on a "traditional" problem that did not seem to exist in the virtual world. As shown in the regression models (Table 6, Table 7), the opposite is true. The virtual space is a certain predictor of risk behavior in the field of psychoactive substance use. Okruhlica (2020) claims that the latest information from the NCZI (Baráková \& Závodská, 2020), the increase in mortality due to alcohol cirrhosis (between 2011 and 2018) by 32\%. Taking into account other diagnoses of drinking mortality, drinking mortality is up to $60 \%$ higher. After this consideration, deaths in Slovakia due to drinking are in 2nd place, behind chronic ischemic heart disease (based on this ranking, there are no oncological diseases included). According to the WHO (2020), Slovakia is one of the countries with the highest proportion of cancer caused by long-term alcohol consumption. It is necessary to think deeply about the given mortality statistics in the context of broader metatheoretical considerations of the ecosystem of the environment of the Slovak Republic, in which the next generations are growing up.

\section{Conclusion}

The effect of several types of risk behavior, together with loneliness, may represent a much higher risk of developing risk and addictive behavior, which is aided by temporally and spatially untied virtual space without borders and formal control. The pseudo-values and experience of ephemeral enjoyment of the "satisfied" emotional need in the virtual world will never fulfill the real basic human needs of affiliation, intimacy, and love. Virtual aspects of the Internet are a standard part of most people's daily lives. The Internet forms its own virtual world, albeit parallel, but difficult to separate from the physical human habitat. The current hyper-period requires considerable effort from man to answer the implicit questions of his being and the exact demands and demands of the social environment in which these claims have an increasing tendency. The simultaneous action of virtual space and the physical eco-social environment can cause adolescents to spend an excessive amount of time on the Internet as a way of relieving perceived tensions in an area where the direct influence of social control agents is weakened or minimal (Hrčka, 2001). Social control of virtual space is only one of many factors that probably require a new perspective or revision of the paradigm of the eco-social framework (Kuhn, 1982; Lemert, 1967; Gitterman \& Germain, 2011). Experiencing emotional and/or social loneliness as a risk factor creates conditions for the use of psychoactive substances, with a desire to meet the basic needs of intimacy, affiliation, and love in the virtual world. The consideration of variables representing aspects of the virtual world should be included in prevention and intervention programs to prevent the emergence and development of risk and addictive behavior.

\section{Acknowledgement}

The article entitled 'Loneliness and predictive models of adolescents' multiple risk behaviors in the context of ecosystem metatheory and virtual space of Internet' pertains to the Vega No. 1/0285/18 'Risk Behavior in Adolescents as Social Work Clients as a Consequence of Loneliness' project.

\section{References}

Akerlind, I., \& Hörnquist, J. O. (1992). Loneliness and alcohol abuse: A review of evidences of an interplay. Social science \& medicine, 34(4), 405-414. https://doi.org/10.1016/0277-9536(92)90300-F

Alcoholics Anonymous, W. S., (2001). Alcoholics Anonymous - Big Book. Alcoholics Anonymous World Services.

Ali, Y. A. (2021). Behavioral Addictions: The Substance of "Non-Substance Related Addictive Disorders". International Journal of Emergency Mental Health and Human Resilience, 23(1), 1-6. https://www.omicsonline.org/openaccess/behavioral-addictions-the-substance-of-nonsubstance-related-addictive-disorders-114737.html

Baliunas, D., Rehm, J., Irving, H., \& Shuper, P. (2010). Alcohol consumption and risk of incident human immunodeficiency virus infection: a meta-analysis. International journal of public health, 55(3), 159-166. https://doi.org/10.1007/s00038-0090095-x 
Baráková, A., \& Závodská, N. (2020). Na čo zomierajú Slováci [What Slovaks are dying for]. Medikom, 10(7), 6-11. https://lekom.sk/files/2/Medikom/SLK\%2007_2020\%20na\%20web.pdf

Barber, J. A., \& Thompson, S. G. (2000). Analysis of cost data in randomized trials: an application of the non-parametric bootstrap. Statistics in medicine, 19(23), 3219-3236. https://doi.org/10.1002/1097-0258(20001215)19:23<3219::AIDSIM623>3.0.CO;2-P

Bays, J. (1990). Substance abuse and child abuse: Impact of addiction on the child. Pediatric Clinics of North America, 37(4), 881-904. https://doi.org/10.1016/S0031-3955(16)36941-3

Bonomo, Y. A., Bowes, G., Coffey, C., Carlin, J. B., \& Patton, G. C. (2004). Teenage drinking and the onset of alcohol dependence: a cohort study over seven years. Addiction, 99(12), 1520-1528. https://doi.org/10.1111/j.13600443.2004.00846.x

Cacioppo, J. T., \& Patrick, W. (2008). Loneliness: Human Nature and the Need for Social Connection. W. W. Norton \& Co. Campbell, A., Taylor, J. T., \& McGlade, A. (2017). Research design in social work. SAGE.

Chen, G. (2010). The meaning of suffering in drug addiction and recovery from the perspective of existentialism, Buddhism and the 12-step program. Journal of psychoactive drugs, 42(3), 363-375. https://doi.org/10.1080/02791072.2010.10400699

Cramer, D. (1997). Fundamental Statistics for Social Research: Step-by-Step Calculations and Computer Techniques Using SPSS for Windows. Routledge.

De Leon, G. (2000). The Therapeutic Community : Theory, Model, and Method. Springer.

Doane, D. P., \& Seward, L. E. (2011). Measuring skewness: a forgotten statistic?. Journal of statistics education, 19(2), 118. https://doi.org/10.1080/10691898.2011.11889611

Durkee, T., Kaess, M., Floderus, B., Carli, V., \& Wasserman, D. (2011). FC09-06-Adolescent internet behaviors and its correlation to depression, self-harm and suicidal behavior in European pupils. European Psychiatry, 26(S2), 1863-1863. https://doi.org/10.1016/S0924-9338(11)73567-2

Durkee, T., Carli, V., Floderus, B., Wasserman, C., Sarchiapone, M., Apter, A., Balazs, A. J., Bobes, J., Brunner, R., Corcoran, P., Cosman, D., Haring, Ch., Hoven, W. Ch., Kaes, M., Kahn, P. J., Nemes, B., Postuvan, V., Saiz, A. P., Värnik, P., \& Wasserman, D. (2016). Pathological internet use and risk-behaviors among European adolescents. International Journal of Environmental Research and Public Health, 13(3), 294. https://doi.org/10.3390/ijerph13030294

Ellis, A., \& Ellis, J. D. (2013). Rational Emotive Behavior Therapy. American Psychological Association.

Erdoğan, Y. (2008). Exploring the relationships among Internet usage, Internet attitudes and loneliness of Turkish adolescents. Cyberpsychology: Journal of Psychosocial Research on Cyberspace, 2(2).

https://cyberpsychology.eu/article/view/4216

Frankl, E. V. (1963). Man 's Search for Meaning. Washington Square Press.

Fraser, D. A. S., Wong, A., \& Wu, J. (1999). Regression analysis, nonlinear or nonnormal: Simple and accurate p values from likelihood analysis. Journal of the American Statistical Association, 94(448), 1286-1294. https:doi/citedby/10.1080/01621459.1999.10473881

Gierveld, J. de J. (1987). Developing and testing a model of loneliness. Journal of personality and social psychology, 53(1), 119-128. https://pubmed.ncbi.nlm.nih.gov/3612484/

Gierveld, J. de J., \& Tilburg, Van G. T. (2021, May 7). Manual of the loneliness scale 1999. Amsterdam: VU University Amsterdam, Department of Social Research Methodology. Retrieved September 1, 2018, from https://home.fsw.vu.nl/tg.van.tilburg/manual_loneliness_scale_1999.html

Gitterman, A., \& Germain, C. B. (2011). Ecological Framework. In L. E. Davis \& T. Mizrahy (Eds.), The Encyklopedia of Social Work. (pp. 97-102). Oxford University Press.

Grayson, D. (2004). Some myths and legends in quantitative psychology. Understanding statistics, 3(2), 101-134. https://doi.org/10.1207/s15328031us0302_3

Griffiths, M. (1999). Gambling technologies: Prospects for problem gambling. Journal of gambling studies, 15(3), $265-283$. https://doi.org/10.1023/A:1023053630588

Griffiths, M. (2005). A 'components' model of addiction within a biopsychosocial framework. Journal of Substance use, 10(4), 191-197. https://doi.org/10.1080/14659890500114359

Hanć, T., Czapla, Z., Szwed, A., Durda, M., Krotowska, A., \& Cieślik, J. (2015). Growth and nutritional status of children from dysfunctional families with alcohol addicted parents in Poland. Economics \& Human Biology, 18, 101-109. https://doi.org/10.1016/j.ehb.2015.05.003

Hosseinbor, M., Yassini Ardekani, S. M., Bakhshani, S., \& Bakhshani, S. (2014). Emotional and social loneliness in individuals with and without substance dependence disorder. International journal of high risk behaviors \& addiction, 3(3), e22688. https://doi.org/10.5812/ijhrba.22688

Hrčka, M. (2001). Sociální deviace [Social deviation]. Sociologické nakladatelsvtí.

Jellinek, E. M. (1952). Phases of alcohol addiction. Quarterly journal of studies on alcohol, 13(4), 673-684. https://doi.org/10.15288/qjsa.1952.13.673

Jessor, R. (1992). Risk behavior in adolescence: A psychosocial framework for understanding and action. Developmental review, 12(4), 374-390. https://doi.org/10.1016/0273-2297(92)90014-S 
Jessor, R. (2014). Problem behavior theory: A half-century of research on adolescent behavior and development. In R. M. Lerner, A. C. Petersen, R. K. Silbereisen \& J. Brooks-Gunn (Eds.). The developmental science of adolescence: History through autobiography (pp. 239-256). Psychology Press, Taylor \& Francis.

Johnson, S., \& Johnson, R. (2009). Conceptualizing and interpreting reliability. Ofqual.

Kaess, M., Durkee, T., Brunner, R., Carli, V., Parzer, P., Wasserman, C., Sarchiapone, M., Apter, A., Balazs, A. J., Bobes, J., Brunner, R., Corcoran, P., Cosman, D., Haring, Ch., Hoven, W. CH., Apter, A., Balazs, J., Balint, M., Cohen,

R.... Wasserman, D. (2014). Pathological Internet use among European adolescents: psychopathology and self-destructive behaviours. European child \& adolescent psychiatry, 23(11), 1093-1102. https://doi.org/10.1007/s00787-014-0562-7

Kahan, J., Lichner, V. \& Žiaková, E. (2021, in press). Risk Behavior of Adolescents in the Slovak Republic: Are adolescents lonely? Ljetopis socijalnog rada / Annual of Social Work. ISSN: 1846-5412

Kahan, J., \& Žiaková, E. (2019). Cez osamelost’ k abstinencii: alebo prečo sú závislí l'udia osamelí. [Through loneliness to abstinence: or why addicted people are lonely]. Univerzita Pavla Jozefa Šafárika.

Kemp, P. S., Whittaker, K. J., \& Tracy, M. E., (1997). Person-Environment Practice: The Social Ecology of Interpersonal Helping. Aldine de Gruyter.

Klassen, A. C., Creswell, J., Clark, V. L. P., Smith, K. C., \& Meissner, H. I. (2012). Best practices in mixed methods for quality of life research. Quality of Life Research, 21(3), 377-380. https://doi.org/10.1007/s11136-012-0122-x

Kuhn, S. T. (1982). Štruktúra vedeckých revolúcií [The structure of scientific revolutions]. Pravda.

Kutner, H. M., Christopher J. N., Neter, J., William L. (2005). Applied Linear Statistical Models. McGraw-Hill.

Lawal, A. M., \& Idemudia, E. S. (2018). Gender difference, class level and the role of internet addiction and loneliness on sexual compulsivity among secondary school students. International Journal of Adolescence and Youth, 23(4), 422-430. https://doi.org/10.1080/02673843.2017.1406380

Lemert, E. (1967). Human Deviance, Social Problems and Social Control. Prentice Hall Inc.

Lochman, J. E., \& van den Steenhoven, A. (2002). Family-based approaches to substance abuse prevention. Journal of Primary Prevention, 23(1), 49-114. https://doi.org/10.1023/A:1016591216363

Lovašová, S. (2021). Adolescencia ako obdobie rizika: rizikové správanie v adolescencii a jeho identifikácia [Adolescence as a risk period: risky behavior in adolescence and its identification]. Univerzita Pavla Jozefa Šafárika.

Lyons, G. C., Deane, F. P., \& Kelly, P. J. (2010). Forgiveness and purpose in life as spiritual mechanisms of recovery from substance use disorders. Addiction Research \& Theory, 18(5), 528-543. https://doi.org/10.3109/16066351003660619

MacArthur, G. J., Smith, M. C., Melotti, R., Heron, J., Macleod, J., Hickman, M., Kipping, R. R., Campbell, R. \& Lewis, G. (2012). Patterns of alcohol use and multiple risk behaviour by gender during early and late adolescence: the ALSPAC cohort. Journal of public health, 34(1), 20-30. https://doi.org/10.1093/pubmed/fds006

Marlatt, G. A. (1996). Taxonomy of high-risk situations for alcohol relapse: evolution and development of a. Addiction, 91(12s1), 37-50. https://doi.org/10.1046/j.1360-0443.91.12s1.15.x

Marlatt, G. A., \& Gordon, R. J. (1985). Relapse Prevention: Maintenance Strategies in the Treatment of Addictive Behaviors. The Guilford Press.

Martin, P. R., \& Petry, N. M. (2005). Are non-substance-related addictions really addictions? The American Journal on Addictions, 14(1), 1-7. https://doi.org/10.1080/10550490590899808

Maslow, H. A. (2013). A Theory of human motivation. Martino Publishing.

McCambridge, J., McAlaney, J., \& Rowe, R. (2011). Adult consequences of late adolescent alcohol consumption: a systematic review of cohort studies. PLoS Med, 8(2), e1000413. https://doi.org/10.1371/journal.pmed.1000413

McKeganey, N. (2002). Substance misuse \& drug addiction. Palgrave MacMillan.

Medora, N. P., \& Woodward, J. C. (1991). Factors associated with loneliness among alcoholics in rehabilitation centers. The Journal of social psychology, 131(6), 769-779. https://doi.org/10.1080/00224545.1991.9924664

Okruhlica, L'. (2020). Alkoholizmus: Slovensku chýba tvrdá reflexia - tu je! [Alcoholism: Slovakia lacks hard reflection here it is!]. Alkoholizmus a drogové závislosti, 55(3-4), 177-180.

Oskenbay, F., Kalymbetova, E., Tolegenova, A., Kabakova, M., Bakiyeva, S., \& Nugmanova, S. (2015). Addictive behavior among adolescents. Procedia-Social and Behavioral Sciences, 171, 406-411. https://doi.org/10.1016/j.sbspro.2015.01.140

Page, R. M., \& Cole, G. E. (1991). Loneliness and alcoholism risk in late adolescence: a comparative study of adults and adolescents. Adolescence, 26(104), 925. https://www.proquest.com/scholarly-journals/loneliness-alcoholism-risk-lateadolescence/docview/195929319/se-2?accountid=16775

Pallant, J. (2007). SPSS - Survival Manual. Maidenhead: Open University Press.

Perlman, D., \& Peplau, L. A. (1982). Theoretical approaches to loneliness. In L. A. Peplau \& D. Perlman (Eds.), Loneliness: A sourcebook of current theory, research and therapy (pp. 123-134). John Wiley \& Sons.

Razali, N. M., \& Wah, Y. B. (2011). Power comparisons of shapiro-wilk, kolmogorov-smirnov, lilliefors and andersondarling tests. Journal of statistical modeling and analytics, 2(1), 21-33.

https://www.nbi.dk/ petersen/Teaching/Stat2019/Power_Comparisons_of_Shapiro-Wilk_Kolmogorov-Smirn.pdf

Rokach, A. (2002). Determinants of loneliness of young adult drug users. The Journal of psychology, 136(6), 613-630. https://doi.org/10.1080/00223980209604823 
Rokach, A., \& Orzeck, T. (2003). Coping with loneliness and drug use in young adults. Social Indicators Research, 61(3), 259-283. https://doi.org/10.1023/A:1021977731756

Sawilowsky, S. S., \& Blair, R. C. (1992). A more realistic look at the robustness and Type II error properties of the $t$ test to departures from population normality. Psychological Bulletin, 111(2), 352-360. https://doi.org/10.1037/0033-2909.111.2.352 Schmider, E., Ziegler, M., Danay, E., Beyer, L., \& Bühner, M. (2010). Is it really robust? Methodology, 6(4), 147-151. https://doi.org/10.1027/1614-2241/a000016

Shapiro, S. S., \& Wilk, M. B. (1965). An analysis of variance test for normality (complete samples). Biometrika, 52(3/4), 591-611. https://doi.org/10.2307/2333709

Stickley, A., Koyanagi, A., Koposov, R., Schwab-Stone, M., \& Ruchkin, V. (2014). Loneliness and health risk behaviours among Russian and US adolescents: a cross-sectional study. BMC public health, 14(1), 1-12. https://doi.org/10.1186/14712458-14-366

Volpicelli, J., \& Szalavitz, M. (2000). Recovery Options: The Complete Guide - How You and Your Loved Ones Can Understand and Treat Alcohol and Other Drug Problems. John Wiley \& Sons Inc.

Weiss, R. S. (1985a). The Study Of Loneliness. In R. S. Weiss (Ed.), Loneliness: The Experience of Emotional and Social Isolation (pp. 7-30). The MIT Press.

Weiss, R. S. (1985b). The Loneliness of Emotional Isolation. In R. S. Weiss (Ed.), Loneliness: The Experience of Emotional and Social Isolation (pp. 87-101). The MIT Press.

Weiss, R. S. (1985c). The Loneliness of Social Isolation. In R. S. Weiss (Ed.), Loneliness: The Experience of Emotional and Social Isolation (pp. 143-154). The MIT Press.

Woititz, G. J. (2002). Adult Children of Alcoholics: at Home, at Work, and in Love. Healt Communications.

World Health Organization. (2020). Regional Office for Europe: Alcohol and cancer in the WHO European Region: An appel for better prevention. https://www.euro.who.int/en/health-topics/disease-prevention/alcoholuse/publications/2020/alcohol-and-cancer-in-the-who-european-region-an-appeal-for-better-prevention-2020

Yen, J. Y., Yen, C. F., Chen, C. C., Chen, S. H., \& Ko, C. H. (2007). Family factors of internet addiction and substance use experience in Taiwanese adolescents. Cyberpsychology \& behavior, 10(3), 323-329. https://doi.org/10.1089/cpb.2006.9948 Zou, Z., Wang, H., Uquillas, F. D. O., Wang, X., Ding, J., \& Chen, H. (2017). Definition of substance and non-substance addiction. Substance and Non-substance Addiction, 21-41. https://doi.org/10.1007/978-981-10-5562-1_2 